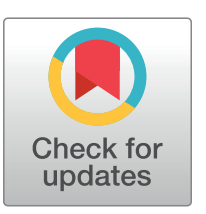

G OPENACCESS

Citation: Kobo 0, Efraim R, Saada M, Kofman N, Abu Dogosh A, Abramowitz Y, et al. (2020) The impact of lockdown enforcement during the SARSCOV-2 pandemic on the timing of presentation and early outcomes of patients with ST-elevation myocardial infarction. PLOS ONE 15(10): e0241149. https://doi.org/10.1371/journal. pone.0241149

Editor: Corstiaan den Uil, Erasmus Medical Center, NETHERLANDS

Received: August 7, 2020

Accepted: October 8, 2020

Published: October 23, 2020

Peer Review History: PLOS recognizes the benefits of transparency in the peer review process; therefore, we enable the publication of all of the content of peer review and author responses alongside final, published articles. The editorial history of this article is available here: https://doi.org/10.1371/journal.pone.0241149

Copyright: @ 2020 Kobo et al. This is an open access article distributed under the terms of the Creative Commons Attribution License, which permits unrestricted use, distribution, and reproduction in any medium, provided the original author and source are credited.

Data Availability Statement: The data underlying the results presented in the study are available
RESEARCH ARTICLE

\section{The impact of lockdown enforcement during the SARSCoV-2 pandemic on the timing of presentation and early outcomes of patients with ST-elevation myocardial infarction}

\author{
Ofer Kobo ${ }^{1 \odot *}$, Roi Efraim ${ }^{2 \odot}$, Majdi Saada ${ }^{1}$, Natalia Kofman ${ }^{3,4}$, Ala Abu Dogosh ${ }^{5}$, \\ Yigal Abramowitz ${ }^{5}$, Doron Aronson ${ }^{2,6}$, Sa'ar Minha $^{3,4}$, Ariel Roguin ${ }^{1,6}$, Simcha R. Meisel ${ }^{1,6}$ \\ 1 Department of Cardiology, Hillel Yaffe Medical Center, Hadera, Israel, 2 Department of Cardiology, \\ Rambam Health Care Campus, Haifa, Israel, 3 Department of Cardiology, Shamir Medical Center, Zerifin, \\ Israel, 4 Sackler Faculty of Medicine, Tel-Aviv University, Tel-Aviv, Israel, 5 Department of Cardiology, \\ Soroka University Medical Center, Faculty of Health Sciences, Ben Gurion University of the Negev, Beer- \\ Sheva, Israel, 6 Rappaport - Faculty of Medicine, Technion - Israel Institute of Technology, Haifa, Israel \\ ๑ These authors contributed equally to this work. \\ * Ofermkobo@gmail.com
}

\section{Abstract}

\section{Introduction}

Early reports described decreased admissions for acute cardiovascular events during the SarsCoV-2 pandemic. We aimed to explore whether the lockdown enforced during the SARSCoV-2 pandemic in Israel impacted the characteristics of presentation, reperfusion times, and early outcomes of ST-elevation myocardial infarction (STEMI) patients.

\section{Methods}

A multicenter prospective cohort comprising all STEMI patients treated by primary percutaneous coronary intervention admitted to four high-volume cardiac centers in Israel during lockdown (20/3/2020-30/4/2020). STEMI patients treated during the same period in 2019 served as controls.

\section{Results}

The study comprised 243 patients, 107 during the lockdown period of 2020 and 136 during the same period in 2019, with no difference in demographics and clinical characteristics. Patients admitted in 2020 had higher admission and peak troponin levels, had a 2.4 fold greater likelihood of Door-to-balloon times $>90 \mathrm{~min}(95 \% \mathrm{Cl}: 1.2-4.9, \mathrm{p}=0.01)$ and 3.3 fold greater likelihood of pain-to-balloon times $>12$ hours (OR 3.3, 95\% Cl: 1.3-8.1, $p<0.01$ ). They experienced higher rates hemodynamic instability $(25.2 \%$ vs $14.7 \%, p=0.04)$, longer hospital stay (median, IQR [4, 3-6 Vs 5, 4-6, $p=0.03]$ ), and fewer early (<72 hours) discharge $(12.4 \%$ Vs $32.4 \%, p<0.001)$. 
upon request because they contain potentially identifying details about the patients. As the number of STEMI admissions in each institute is limited, the date and time of admission, gender and age are enough to identify patients. The Hillel Yaffe Helsinki Committee imposed these data sharing restrictions. Data requests should be sent to the Ms Naama Amsalem, Cardiology Research Coordinator, Hillel Yaffe Hospital-NaamaA@hy. health.gov.il.

Funding: The author(s) received no specific funding for this work.

Competing interests: The authors have declared that no competing interests exist.

\section{Conclusions}

The lockdown imposed during the SARSCoV-2 pandemic was associated with a significant lag in the time to reperfusion of STEMI patients. Measures to improves this metric should be implemented during future lockdowns.

\section{Introduction}

Although the pathophysiological mechanism is not fully known, the incidence of acute myocardial infarctions is expected to increase during times of stress [1-4]. In addition to the economic crisis precipitated by the SARS-CoV-2 pandemic, it impacted on the wellbeing of the global population by imposing social restrictions associated with anxiety and stress. However, one of the lockdown consequences was the withdrawal of patients and a tendency to avoid referral to hospitals. Early reports suggested fewer Acute Coronary Syndrome (ACS)-related admissions [5-9] with longer times from symptom onset to medical contact [7, 10]. On March $20^{\text {th }}$, due to the rising SARS-CoV-2 morbidity (S1 Table), a lockdown was enforced in Israel. We aimed to examine the impact of the government-imposed lockdown in Israel on the characteristics of presentation, reperfusion times and early outcomes of ST-elevation myocardial infarction (STEMI) patients.

\section{Methods}

The current analysis is based on a multicenter prospective cohort from four high-volume cardiac centers in Israel- Hillel Yaffe Medical Center, Rambam Healthcare Campus, Shamir Medical Center and Soroka Medical Center. All participating centers are university-affiliated hospitals with coronary catheterization-laboratories that provide a $24 / 7$ on-call primary PCI (PPCI) service. The study was conducted according to the Declaration of Helsinki, with informed consent being waived due to the observational nature of the study.

Data of all consecutive patients presenting with STEMI, during the lockdown period in Israel, March $20^{\text {th }}$-end of April 2020 were entered into a dedicated database and compared with retrospective data from the same period in 2019. The Inclusion criterion was a diagnosis of STEMI on admission. The main exclusion criterion was age $<18$.

The primary endpoints were door-to-balloon(D2B) and pain-to-balloon time intervals (P2B). Secondary endpoints included in-hospital mortality, failure to achieve post-PCI TIMI3 flow, moderately- or severely-reduced left ventricular ejection fraction $(<40 \%)$ at discharge, need for mechanical ventilation, hemodynamic instability during hospitalization, length of hospital stay, and baseline and peak high sensitivity-troponin level.

Reperfusion times, as well as post PCI TIMI flow were drawn from the PCI report. Hemodynamic instability was defined as a need for vasopressors, cardiogenic shock, or use of mechanical circulatory support.

Multivariable logistic regression models were used to examine the association between 2020 admission and delayed reperfusion intervals. Models were adjusted to baseline demographics and risk factors with 2019 admissions serving as a reference group.

Categorical variables were presented as frequencies and percentages and compared using Pearson's chi-square test or the Fisher-exact test. Continuous variables were presented as median and interquartile range or mean and standard deviation compared using the T-test or the Mann-Whitney $\mathrm{U}$ test, as appropriate. A p-value $<0.05$ was considered statistically 
significant. Data analysis was performed using IBM SPSS Statistics for Windows (Version 25.0, Armonk, NY).

\section{Results}

Two-hundred and forty- three patients were included in the study including 136 during March 20-April 302019 and 107 during March20 -April 302020 (22\% decrease). Overall, 7 patients did not undergo PCI (three in 2019, four in 2020, $\mathrm{p}=0.37$ ). Only one SARS-CoV-2 positive patient was included in the study. Data on reperfusion time was available for all patients. There were no significant differences in patient demographics and clinical characteristics between the groups. P2B time was significantly longer in 2020, with a higher rate of patients presenting with very-long ( $>12$ hours) P2B intervals and a higher rate of patients failing to meet the $\mathrm{D} 2 \mathrm{~B}<90$ minutes guideline constraint. More patients in 2020 developed hemodynamic instability, and their admission and peak troponin levels were higher $(\mathrm{p}=0.03,0.01$, respectively). More patients were discharged early ( $<72$ hours) in 2019 as reflected in a significant difference in hospital length of stay (Table 1). No significant difference in other in-hospital outcomes was noted.

In the 2020 group, the adjusted odds for delayed reperfusion times were significantly higher both for D2B $>90$ min (OR-2.4, 95\%CI:1.2-4.9, $\mathrm{p}=0.01$ ) and P2B $>12$ hours (OR3.3, 95\% CI:1.3-8.1, $\mathrm{p}<0.01$, Table 2, Fig 1).

\section{Discussion}

The present multicenter study aimed to evaluate the influence of SARS-CoV-2 pandemic and its attendant government restrictions on the timeliness of STEMI presentation and early outcomes. In contrary to the anticipated rise in cardiovascular events [1-4], early reports revealed a decrease in ACS admissions during the SARS-CoV-2 pandemic [5-9]. Correspondingly, we found a significant $22 \%$ decrease in the incidence of STEMI presentations during the lockdown period, compared with the same period in 2019. Possible explanations for this decrease were previously suggested [7] and include a change in lifestyle during the lockdown, fear from contacting SARS-CoV-2 patients in the hospitals, dismissing ACS symptoms as viral related, and avoiding any unnecessary burden on the strained medical staff.

Reperfusion times directly affect the clinical outcomes of STEMI patients [11-13]. We observed a 2.4-fold greater likelihood of prolonged D2B ( $>90 \mathrm{~min}$ ) and a 3.3-fold greater likelihood of prolonged P2B ( $>12$ hours) during lockdown as compared to 2019.

The delayed P2B time may share similar causes as the decrease in the incidence of STEMI. There was no change in the PPCI pathway or STEMI admission policy during the lockdown period. Admitted patients were tested for SARSCoV-2 according to the Ministry of Health guidelines but their admission and treatment were not delayed. However, the increased D2B time may be partly explained by the need of the medical staff to put on personal protective equipment, as well as emergency department (ED) increased workload (for those who arrived through ED). While these differences did not translate to a significant difference in in-hospital mortality (though a nominal increase was observed), both admission and peak troponin levels were higher, and more patients developed hemodynamic instability throughout their hospitalization in the 2020 patient group. The length of hospital stay was longer, and fewer patients were discharged early following PPCI despite a general tendency to shorten the length of hospital stay during the pandemic. These may serve as surrogate markers of severity, with an expected worse long-term prognosis.

Several limitations of this study should be acknowledged. First, we compared the contemporary cohort data to a retrospective one, with its inherent limitation. Second, our short 
Table 1. Patients' clinical characteristics and in hospital outcomes.

\begin{tabular}{|c|c|c|c|}
\hline & $2019(n=136)$ & $2020(n=107)$ & P value \\
\hline Age, year Median (IQR) & $61(51,68)$ & $63(52,70$ & 0.33 \\
\hline Women, \% & 18.4 & 15.9 & 0.61 \\
\hline Ischemic Heart Disease, \% & 33.8 & 27.1 & 0.26 \\
\hline Diabetes Mellitus, \% & 29.4 & 34.6 & 0.48 \\
\hline Hypertension, \% & 47.8 & 52.3 & 0.48 \\
\hline Dyslipidemia, \% & 53.7 & 58.9 & 0.42 \\
\hline Smoker, \% & 61 & 63.6 & 0.88 \\
\hline Atrial Fibrillation, \% & 6.6 & 7.5 & 0.79 \\
\hline Family History of Ischemic Heart Disease, \% & 17.8 & 24 & 0.24 \\
\hline \multicolumn{3}{|l|}{ Infarct Related Artery (IRA) } & \multirow[t]{6}{*}{0.53} \\
\hline LMCA & 2.2 & 2.8 & \\
\hline LAD & 47.4 & 36.8 & \\
\hline LCX/Ramus intermedius & 11.1 & 12.1 & \\
\hline RCA & 37.8 & 45.3 & \\
\hline SVG grafts & 1.5 & 1.9 & \\
\hline Multivessel Disease & 56.6 & 55.1 & 0.82 \\
\hline \multicolumn{3}{|l|}{ Pre PCI TIMI flow in IRA, $\%$} & \multirow[t]{5}{*}{0.26} \\
\hline TIMI 0 & 54.1 & 50 & \\
\hline TIMI 1 & 8.9 & 5.7 & \\
\hline TIMI 2 & 12.6 & 21.7 & \\
\hline TIMI 3 & 24.4 & 22.6 & \\
\hline P2B, hours median (IQR) & $3(2,5.75)$ & $4(3,8.5)$ & 0.01 \\
\hline D2B, Min median (IQR) & $49(31,75)$ & $56(30,89)$ & 0.22 \\
\hline $\mathrm{D} 2 \mathrm{~B}>90 \mathrm{~min}$ & 11.9 & 24 & 0.01 \\
\hline$\underline{\mathrm{P} 2 \mathrm{~B}>12 \text { hours }}$ & 7.6 & 19 & 0.01 \\
\hline Inability to achieve TIMI 3 flow post PCI, \% & 5.9 & 8.5 & 0.44 \\
\hline Admission Troponin, ng/L median (IQR) & $54(20,623)$ & $150(43,608)$ & 0.03 \\
\hline Peak Troponin, ng/L median (IQR) & $2,648(1,033,6,300)$ & $4,365(2,000,10,000)$ & 0.01 \\
\hline CCU length of stay, Days median (IQR) & $3(3,4)$ & $4(3,5)$ & 0.24 \\
\hline Hospital length of stay, Days median (IQR) & $4(3,6)$ & $5(4,6)$ & 0.03 \\
\hline Early Discharge, \% & 32.4 & 12.4 & $<0.001$ \\
\hline Mechanical Ventilation, \% & 13.2 & 12.1 & 0.81 \\
\hline Hemodynamic instability, \% & 14.7 & 25.2 & 0.04 \\
\hline VF/ Cardiac arrest, \% & 12.5 & 14 & 0.73 \\
\hline LVEF (, \% median (IQR) & $42(35,55)$ & $43(35,50)$ & 0.66 \\
\hline Reduced LVEF,\% & $46.6 \%$ & $46.6 \%$ & 0.99 \\
\hline Mortality, \% & 5.2 & 8.4 & 0.32 \\
\hline
\end{tabular}

https://doi.org/10.1371/journal.pone.0241149.t001

follow-up and the relatively small sample size do not allow us to conclude on hard endpoints such as mortality. However, it should be noted that the association between prolonged reperfusion times and outcomes is well established [11-13].

\section{Conclusion}

The lockdown imposed in March -April 2020 during the SARSCoV-2 pandemic was associated with a fewer STEMI admission and a significant lag in the time intervals to reperfusion, higher troponin levels and longer hospital stays of STEMI patients. As reperfusion times 
Table 2. Adjusted* odds ratio for delayed reperfusion times.

\begin{tabular}{c|c|c}
\hline & \multicolumn{2}{|c}{ Lockdown period 2020 } \\
\hline & OR $(\mathbf{9 5 \%} \mathrm{CI})$ & P value \\
\hline $\mathrm{D} 2 \mathrm{~B}>90$ min & $2.4(1.2-4.9)$ & 0.01 \\
\hline $\mathrm{P} 2 \mathrm{~B}>12$ hours & $3.3(1.3-8.1)$ & $<0.01$ \\
\hline
\end{tabular}

D2B: Door-to-Balloon, P2B: Pain-to-Balloon

Reference group: 2019 admissions; Adjusted to age, gender, ischemic heart disease, hypertension, Smoker, diabetes mellitus, and dyslipidemia. D2B: Door-to-Balloon, P2B: Pain-to-Balloon

https://doi.org/10.1371/journal.pone.0241149.t002

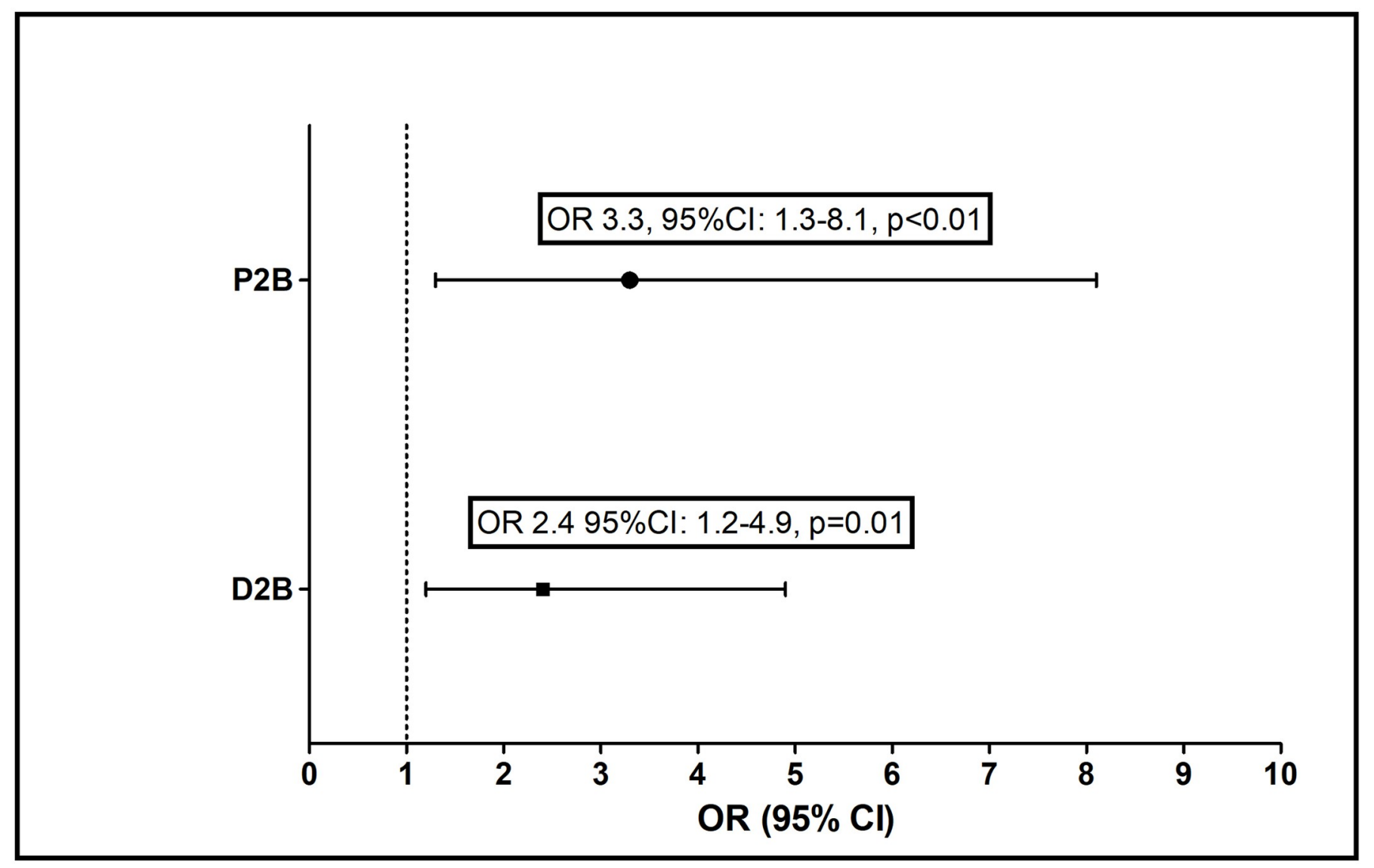

Fig 1. Adjusted ${ }^{*}$ odds ratio for delayed reperfusion times. * Reference group: 2019 admissions; Adjusted to age, gender, ischemic heart disease, hypertension, Smoker, diabetes mellitus, and dyslipidemia. D2B: Door-to-Balloon, P2B: Pain-to-Balloon.

https://doi.org/10.1371/journal.pone.0241149.g001

directly affect the clinical outcomes of STEMI patients, measures to improve these metrics should be implemented prior to and during any future lockdown.

\section{Supporting information}

S1 Table. Weekly confirmed new SARS-CoV-2 cases in Israel during lockdown.

(DOCX) 


\section{Author Contributions}

Conceptualization: Ofer Kobo, Roi Efraim, Sa'ar Minha.

Data curation: Majdi Saada, Ala Abu Dogosh.

Methodology: Ofer Kobo, Roi Efraim.

Writing - original draft: Ofer Kobo, Roi Efraim.

Writing - review \& editing: Ofer Kobo, Majdi Saada, Natalia Kofman, Ala Abu Dogosh, Yigal Abramowitz, Doron Aronson, Sa'ar Minha, Ariel Roguin, Simcha R. Meisel.

\section{References}

1. Meisel SR, Kutz I, Dayan KI, Pauzner H, Chetboun I, Arbel Y, et al. Effect of Iraqi missile war on incidence of acute myocardial infarction and sudden death in Israeli civilians. Lancet (London, England). 1991 Sep; 338(8768):660-1.

2. Leor J, Poole WK, Kloner RA. Sudden cardiac death triggered by an earthquake. N Engl J Med. 1996 Feb; 334(7):413-9. https://doi.org/10.1056/NEJM199602153340701 PMID: 8552142

3. Swerdel JN, Janevic TM, Cosgrove NM, Kostis JB. The effect of Hurricane Sandy on cardiovascular events in New Jersey. J Am Heart Assoc. 2014 Dec; 3(6):e001354. https://doi.org/10.1161/JAHA.114. 001354 PMID: 25488295

4. Allegra JR, Mostashari F, Rothman J, Milano P, Cochrane DG. Cardiac events in New Jersey after the September 11, 2001, terrorist attack. J Urban Health. 2005 Sep; 82(3):358-63. https://doi.org/10.1093/ jurban/jti087 PMID: 16000653

5. De Rosa S, Spaccarotella C, Basso C, Calabrò MP, Curcio A, Filardi PP, et al. Reduction of hospitalizations for myocardial infarction in Italy in the COVID-19 era. Eur Heart J. 2020 May;

6. De Filippo O, D'Ascenzo F, Angelini F, Bocchino PP, Conrotto F, Saglietto A, et al. Reduced Rate of Hospital Admissions for ACS during Covid-19 Outbreak in Northern Italy. The New England journal of medicine. 2020.

7. Secco GG, Zocchi C, Parisi R, Roveta A, Mirabella F, Vercellino M, et al. Decrease and Delay in Hospitalization for Acute Coronary Syndromes during the 2020 SARS-CoV-2 Pandemic. Can J Cardiol [Internet]. 2020; Available from: http://www.sciencedirect.com/science/article/pii/S0828282X2030502X

8. Metzler B, Siostrzonek P, Binder RK, Bauer A, Reinstadler SJ. Decline of acute coronary syndrome admissions in Austria since the outbreak of COVID-19: the pandemic response causes cardiac collateral damage. Eur Heart J. 2020;1852-3. https://doi.org/10.1093/eurheartj/ehaa314 PMID: 32297932

9. Garcia S, Albaghdadi MS, Meraj PM, Schmidt C, Garberich R, Jaffer FA, et al. Reduction in ST-Segment Elevation Cardiac Catheterization Laboratory Activations in the United States during COVID-19 Pandemic. Journal of the American College of Cardiology. 2020.

10. Tam C-CF, Cheung K-S, Lam S, Wong A, Yung A, Sze M, et al. Impact of Coronavirus Disease 2019 (COVID-19) Outbreak on ST-Segment-Elevation Myocardial Infarction Care in Hong Kong, China. Vol. 13, Circulation. Cardiovascular quality and outcomes. 2020. p. e006631.

11. Ibanez B, James S, Agewall S, Antunes MJ, Bucciarelli-Ducci C, Bueno H, et al. 2017 ESC Guidelines for the management of acute myocardial infarction in patients presenting with ST-segment elevation: The Task Force for the management of acute myocardial infarction in patients presenting with ST-segment elevation of the European Soci. Eur Heart J. 2018 Jan; 39(2):119-77. https://doi.org/10.1093/ eurheartj/ehx393 PMID: 28886621

12. Nepper-Christensen L, Lønborg J, Høfsten DE, Sadjadieh G, Schoos MM, Pedersen F, et al. Clinical outcome following late reperfusion with percutaneous coronary intervention in patients with ST-segment elevation myocardial infarction. Eur Hear journal Acute Cardiovasc care. 2020 May;2048872619886312.

13. De Luca G, Suryapranata H, Ottervanger JP, Antman EM. Time delay to treatment and mortality in primary angioplasty for acute myocardial infarction: every minute of delay counts. Circulation. 2004 Mar; 109(10):1223-5. https://doi.org/10.1161/01.CIR.0000121424.76486.20 PMID: 15007008 